\title{
Fenomenologias de Edmund Husserl e Alfred Schütz em contribuição à metodologia sociológica
}

\author{
Phenomenology of Edmund Husserl and Alfred Schutz in \\ contribution to sociological methodology
}

Marina Félix de Melo

Resumo: O presente trabalho tem por objetivo discutir algumas das contribuições de Edmund Husserl (1859-1938) e Alfred Schütz (1899-1959) para estudos metodológicos na perspectiva fenomenológica. Busca-se entender porque a fenomenologia é desenhada por formatos diferentes em um olhar que se volta mais à análise filosófica e, outro, mais sociológica, ou mesmo como Schütz apresenta a relação que a filosofia de Husserl tinha com a sociologia.

Palavras-Chave: Fenomenologia; Metodologia das Ciências Sociais; Husserl; Schütz.

\begin{abstract}
The present paper discusses some of the contributions of Edmund Husserl [1859-1938] and Alfred Schütz [1899-1959] in methodological studies in phenomenologic perspective. Therefore, we seek to understand how the phenomenology is drawn for different formats in philosophical and sociological analysis or how Schütz builds the relation between Husserl's philosophy and sociology.
\end{abstract}

Keywords: Phenomenology; Social Science Methodology; Husserl; Schütz.

\section{Fenomenologia}

Entendemos metodologia como uma atividade crítica que diz respeito às etapas da construção do conhecimento, pela qual se pode questionar, inclusive, o próprio cientificismo e a ideia de ciência. Diferentemente dos estudos de métodos e técnicas em ciências sociais (as

Latitude, Vol. 10, no 1, pp. 24-49, 2016

DOI: https://doi.org/10.28998/2179-5428.20160102 
Fenomenologias de Edmund Husserl e Alfred Schütz em contribuição à metodologia sociológica

ferramentas de como operar uma pesquisa), a metodologia se preocupa com os problemas ontológicos arraigados nas teorias das quais fazemos uso no labor do trabalho sociológico. Dito de outra forma, toda teoria tem uma ontologia na medida em que considera alguns aspectos da realidade como reais - o que Max Weber considera como realidade não é a mesmo considerado por Émile Durkheim, por exemplo - e é sobre tais aspectos que nos propomos investigar, sobre como Husserl e Schütz partiram de pontos semelhantes para problematizar e erguer a fenomenologia.

Embora partindo de uma mesma vertente, os dois autores, ao proporem a fenomenologia como uma abordagem anti-naturalista, possuem pontos de aproximação, distanciamento - e mesmo continuidade ao defenderem a fenomenologia como perspectiva de análise. Para entendermos a construção de cada um convém perpassarmos, em um primeiro momento, do que trata tal perspectiva.

É possível que uma boa forma para começar a pensar em fenomenologia seja entender o que é um fenômeno. Se para os racionalistas fenômeno é aquilo que se apresenta pela ideia, não pela sensação, ou se é um evento para os empiristas, para os fenomenólogos é aquilo que se coloca à consciência, é para onde a intencionalidade está dirigida. Sendo assim, para a fenomenologia os fenômenos são coisas que se apresentam à nossa consciência e que, no entanto, dependem de experiência, memória, imaginação, desejo, volição etc na medida em que podemos experimentar tudo isso, pois, o objeto da fenomenologia não é o que está fora da mente, mas sim, dentro. Desta maneira, por exemplo, mais do que a ocorrência em si de um acidente automobilístico, para a fenomenologia o fenômeno estaria ligado às percepções que os sujeitos têm diante do acidente, no terreno das significações, da consciência e entendimento do que significa um acidente para os sujeitos. A ratificar o que versamos, Brentano (1874) coloca, por um recorte psicológico, o fenômeno como algo que ocorre na mente, logo, fenômenos mentais seriam atos de consciência e fenômenos físicos seriam objetos de percepção externa. Estes últimos, para o autor, existem intencionalmente nos atos de consciência. Sinteticamente, podemos entender que o fenômeno se refere ao que temos consciência, a objetos e eventos que nos cercam, bem como à consciência de nossas experiências. “(...) Fenômenos são coisas que são dadas a nossa consciência, por percepção, imaginação ou volição" [Smith, 2008/Stanford encyclopedia of philosophy]. 
Marina Félix de Melo

Em termos fenomenológicos, para que algo tenha significado é preciso que tenhamos consciência sobre ele, assim, a experiência tem significado pela consciência, sendo esta última pré-reflexiva [não pensamos o mundo, vivemos o mundo]. São as técnicas dessa consciência que a fenomenologia se propõe estudar. Para um empirista, nós vemos uma cadeira, todas suas partes constitutivas por completo, entretanto, para um fenomenólogo, basta que vejamos parte da cadeira para que imaginemos o restante do objeto, pois a nossa consciência e experiências completam para nós a construção do que é um objeto cadeira. [Alexander, 1987, p. 245]. O mesmo princípio se aplica a coisas não-materiais como amor, democracia, valores etc (elementos abstratos). O que nos leva, então, à definição de fenomenologia de Smith:

(...) A fenomenologia estuda a estrutura de vários tipos de experiência que vão desde a percepção, o pensamento, a memória, a imaginação, a emoção, desejo e vontade a consciência corporal, a ação corporificada, e atividade social, incluindo a atividade linguística. A estrutura dessas formas de experiência tipicamente envolve o que Husserl chamou de "intencionalidade", ou seja, o direcionamento da experiência em relação às coisas do mundo, de propriedade da consciência de que é uma consciência de ou sobre alguma coisa. [Smith, 2008/Stanford encyclopedia of philosophy] (grifos e tradução nossos).

Na medida em que diz respeito à consciência, em como lidamos com esta, a fenomenologia entende a mente humana como um papel ativo na construção do conhecimento. Sob uma análise filosófica, e associada às contribuições de Husserl e da filosofia européia, se refere à descrição dos fenômenos humanos, da experiência humana especificamente, em como se apresentam tais experiências independentemente da história, do contexto social, da causalidade ou das particularidades dessas experiências. A uma perspectiva "mais sociológica", aqui alentada pela obra de Schütz, é o estudo de como os indivíduos vivenciam o cotidiano e atribuem significados a este e as suas atividades. Autores influenciados pelo 
Fenomenologias de Edmund Husserl e Alfred Schütz em contribuição à metodologia sociológica

existencialismo, como Sartre e Merleau-Ponty, salientam a experiência de sujeitos humanos concretos, que vivem juntos, diferentemente de Husserl que, embebido de um racionalismo cartesiano, mira a experiência do ego individual na busca dos fundamentos essenciais do conhecimento. [Outhwait; Bottomore, 1996, p. 307].

A fenomenologia vem sendo usada com ou sem essa nomenclatura há muitos séculos e, ao que tudo indica, a escola de Lambert (1764), seguidora de Christian Wolff, foi a criadora do termo. Também conhecida como fruto do egocentrismo da filosofia européia, a fenomenologia foi utilizada em diferentes sentidos por diversos pensadores como Kant, Hegel, Hamilton e Hartmann. Como versa Smith, quando os filósofos hindus ou budistas refletiam sobre os estados de consciência ou quando Descartes, Kant ou Hume caracterizavam os estados de percepção, estavam praticando fenomenologia. [Op. cit].

Kant [1786] utilizou o termo em vários sentidos por diversos escritos e o utilizou para ilustrar o segmento da teoria do movimento que entende tanto o repouso quanto o movimento de uma determinada matéria apenas em relação com as modalidades em que ela se coloca externamente. Kant se refere não apenas às características gerais dos fenômenos, ao passo que volta suas lentes à preocupação com a representação destes ao levantar a problemática da descrição da consciência e da experiência, buscando abstrair o conteúdo intencional destas últimas.

Hegel, por sua vez, enxergou na "Fenomenologia do espírito" as etapas sucessivas de aproximação e oposição pelas quais o indivíduo parte da sensação individual à razão universal [Lalande, 1999, p. 397]. Para ele, a fenomenologia é uma investigação histórica da evolução da autoconsciência, desenvolvida pela experiência sensorial primária até atingir processos de pensamentos capazes de engendrar conhecimento.

De acordo com Reale e Antiseri, em "História da Filosofia", Hegel concebe a "Fenomenologia do espírito" na intenção de purificar a consciência empírica e elevá-la, de forma mediata, ao Espírito do saber absoluto [Reale; Antiseri, 1991, p. 112]. A fenomenologia, que por Hegel nos leva da consciência empírica ao saber absoluto, seria então algo como uma introdução à filosofia, contudo, tal iniciação à filosofia já seria, em si, filosofia. Nota-se, ainda, que o absoluto é o cimento do pensamento hegeliano, é ao mesmo tempo sujeito e objeto (a filosofia é o conhecimento do absoluto), e o "motor que eleva a consciência". Tendo em vista essa 
Marina Félix de Melo

relação de Hegel com o absoluto, sintetizamos que a fenomenologia para o autor é a ciência do espírito, na qual "o indivíduo deve percorrer novamente os graus de formação do espírito universal, também segundo o conteúdo, mas como figuras já postas do Espírito, como graus de caminho já traçados e aplainados" [Hegel apud Reale \& Antiseri, 1991, p. 113]. Tais graus são as etapas da história da civilização que as consciências dos sujeitos devem reconhecer e entender como uma projeção.

Em meados de 1899, Franz Brentano utilizou o termo para caracterizar o que entendia por "psicologia descritiva" [Smith, 2008]. Trabalhou em uma perspectiva semelhante à de Hamilton (1859-1869) que, por seu turno, também entende fenomenologia como psicologia descritiva e foi com tal descrição da aparência psíquica que o termo passou a ser utilizado com frequência pela filosofia alemã da segunda metade do século XIX. Já Hartmann se dedicou à "fenomenologia da consciência moral", para ele, uma coletânea de dados empíricos da consciência moral, independentemente de interpretação especulativa, isto é, um inventário de fatos da consciência moral empiricamente conhecidos e de suas relações.

Tentemos resumir em termos práticos tantas contribuições. A socialização, a que somos expostos desde o nascimento, abraça a percepção e a interpretação de mundo do sujeito, sobre como este está no universo que o cerca. Assim, somos educados a aceitar o mundo, compreendê-lo, sem discuti-lo, para que suas noções nos pareçam "naturais". A fenomenologia vem contestar justamente o que já internalizamos como "natural" na medida em que se preocupa com o desfazer destes processos de naturalização. "Por que em minha cultura sou obrigada a me vestir com determinados trajes em dadas ocasiões?" Quando a fenomenologia nos pede para colocarmos em reserva, suspender - eis seu principal verbo: "suspender" - as noções recebidas pela cultura, pede para que questionemos nossa própria cultura, o que não significa, necessariamente, rejeição ou abolição dessa, mas sim, um longo processo reflexivo, mesmo porque o homem não vive em sociedade sem uma cultura.

Platão, ao estabelecer uma distinção entre a simples opinião e o conhecimento, já planta as sementes dessa "suspensão" visada pela fenomenologia, pois, eleva o conhecimento em detrimento à simples opinião, noção que se expressa e se solidifica numa perspectiva ocidental de ciência. A ciência (ao menos a ciência empírica) só tem a validez de um determinado conhecimento até que outro conhecimento, uma nova 
Fenomenologias de Edmund Husserl e Alfred Schütz em contribuição à metodologia sociológica

pesquisa, verse o contrário [ou modifique algo do conhecimento primeiro] e volte-se à suspensão - ou a outras "verdades". [Wolff, 1980, p. 652]. Para tanto, pesquisas são realizadas cotidianamente a partir de hipóteses e verificações. Sinteticamente, podemos denotar que este princípio de suspensão e questionamento do que nos parece "natural" é a fenomenologia que, articulada a isso, se ocupa da estrutura de vários tipos de experiência vindas da memória, do pensamento, da percepção, volição, desejo etc, sendo todas envolvidas no que Husserl vem chamar de intencionalidade e no saber de que consciência é sempre consciência de alguma coisa. [Smith, 2008/Stanford encyclopedia of philosophy].

\section{Edmund Husserl (1849 - 1938)}

Nascido na Alemanha em 1849, Edmund Husserl era de uma família judaica da localidade de Moravia. Em 1887 converte-se ao cristianismo e à Igreja Luterana. Com formação em matemática e buscando identificar estruturas fundamentais da consciência, lecionou em diversas instituições de ensino, em Halle, Göttingen, Friburgo e, mesmo depois de aposentado, realizou pesquisas em Friburgo, até ser "afastado" devido sua procedência judaica. Jeffrey Alexander (1987) versa sobre como o pensamento de Husserl se desenvolve em meio a um contexto de crise intelectual européia, marcado por rigidez e objetividade, no mesmo período de levantamento de um pensamento pragmático nos Estados Unidos, momento de crise intelectual e instabilidade marcado por muita ansiedade, conhecido como "the age of anxiety" [Alexander, 1987, p. 241]. Neste contexto, Husserl foi o propositor de uma fenomenologia transcendental, inspirada numa crítica da razão. Desenvolveu pesquisas na área matemática, numa combinação desta última com a filosofia empírica, de modo a entender como determinados processos mentais eram necessários para a formação do conceito numérico, o que culminou, em 1901, na obra "As investigações lógicas". Aluno de Franz Brentano e Carl Stumpf e sob influência de Descartes e Freje, influenciou alemães e franceses como Martin Heidegger, Edith Stein, Sartre, Merleau-Ponty, Lévinas e Derrida. Em 1938, Husserl falece na cidade de Friburgo.

Husserl pode ser considerado como criador da fenomenologia, sobretudo, com o seu lema de "De volta às coisas". Este "voltar às coisas" é, como já mencionado, colocar em questão as noções recebidas, suspender 
Marina Félix de Melo

nossa cultura para compreender como as coisas aparecem na realidade, isto é, não apenas pelo véu de nossa cultura [Wolff, 1980, p. 652]. Para ele, devemos questionar a maneira pela qual nos ensinaram o mundo e, ao questioná-la, começamos a filosofar. É justamente a dificuldade para tal que levou Husserl a falar da filosofia como uma "ciência rigorosa". Desta preocupação, surge em 1901 o ensaio "A Filosofia como ciência rigorosa", uma maneira de dizer "volte às coisas". Em sua filosofia, a fenomenologia pode ser entendida como uma descrição de fenômenos da experiência humana, como eles se colocam independentemente de contexto social, histórico etc. Como bem sintetiza Alexander:

A fenomenologia é a "ciência a priori". Ela estuda as regras que a consciência segue para fazer as coisas parecerem reais. A percepção apresenta as coisas do mundo como autênticas e interligadas, enquanto realidade, na visão de Husserl, é na verdade um fluxo desconexo de eventos atomizados. A análise fenomenológica mostra como a consciência, através de performances ocultas, transforma esta realidade objetiva em algo completamente diferente, em uma imagem de uma coisa transcendental, objetiva, autêntica e integrada. [Alexander, 1987, p. 244]. (tradução nossa).

Assim como Hegel na criação da obra "Fenomenologia da Mente" (1807) à época da Revolução Francesa (que em vez de levar o povo à liberdade, levou-o ao despotismo novo, de Napoleão), Husserl também produziu em um período crítico, acreditando que toda cultura ocidental se encontrava numa situação extrema de falta de reflexão e que a filosofia fenomenológica poderia contribuir em tal problema. Essa tentativa de compreensão fomentou, em 1936, a obra: "Crise das Ciências Européias e a Fenomenologia Transcendental". O estudo de Hegel sobre fenomenologia em muito se assemelha ao de Husserl, pois, ambos são investigações da consciência, entretanto, uma consciência não restrita à perspectiva da Psicologia Empírica, na qual esta é analisada a partir do senso comum, do mundo "mundano", ordinário. O mais curioso é que apesar das 
Fenomenologias de Edmund Husserl e Alfred Schütz em contribuição à metodologia sociológica

semelhanças entre as perspectivas tratadas por pelos dois autores, alunos de Husserl denotam que o mestre afirmava nunca ter lido Hegel. Eis, talvez, um dos motivos mais incisivos para que vejamos hoje na obra de Husserl uma influência mais concreta do pensamento de Descartes [1637], bem como de Franz Brentano.

Em que medida, todavia, o pensamento cartesiano de Descartes poderia influenciar na filosofia fenomenológica de Husserl? Descartes preocupou-se com o que devemos acreditar acima de qualquer dúvida, e, embora tal preocupação se assemelhe, e muito, com os problemas levantados por Husserl, tal inquietação de Descartes é, apenas, um dos braços da problemática maior da fenomenologia a qual Husserl se dedicou. Embora as questões de Descartes viessem a calhar como um combustível para Husserl, acreditamos que a obra de Brentano, com quem Husserl estudou, tenha uma influência maior ou equivalente em sua fenomenologia. Com Brentano, Husserl estudou o conceito de intencionalidade da consciência, alicerce de sua fenomenologia, que à época da filosofia escolástica foi motivo de grande entusiasmo, mas que havia sido colocada de lado há certo tempo.

Tendo em mente que o noema (fenômeno) e o noesis (abordagem que dele fazemos) podem sofrer modificações ${ }^{1}$, tais modificações se ligam ao problema da evidência. Holisticamente, compreendemos que na concepção fenomenológica a evidência é o fato de alguma coisa "ser assim" ou "ser dessa forma". Logo, a evidência possibilita referir experiências derivadas, bem como experiências originárias, noções imbricadas às reflexões de Husserl de "volta às coisas". Outra importância de distinção entre experiências originárias e derivadas é que dentro da memória existe uma bifurcação entre "retenção" e "lembrança". A retenção se refere à memória imediata do passado, do passado próximo, em contraposição à lembrança, que diz respeito a um passado mais distante. Ao pensarmos em futuro, os termos "protensão" e "antecipação" fazem às vezes do que ocorrerá em breve e de um futuro mais distante, respectivamente. Essas diferenciações, aparentemente restritas a meras interpretações gramaticais, demonstram como um fenômeno percebido tem um horizonte interior e exterior, da mesma forma que as cogitações são rodeadas de "retenções" e

\footnotetext{
${ }^{1}$ Modificações noemáticas [pluralidade de formas pelas quais um fenômeno pode ser visto por nós] e modificações noéticas, as abordagens destes.
} 
Marina Félix de Melo

"protensões", que se relacionam com demais cogitações e assim sucessivamente. [Wolff, 1980, p. 657]. Vale salientar que Husserl tem como ponto de partida a experiência do agente consciente, dessa maneira, as formas de consciência se conectam ao conteúdo das experiências, algo que, para ele, está dado em toda experiência e, por isso, um objeto é construído a partir da síntese de diferentes perspectivas.

O conhecimento que detemos de um objeto é o sedimento de processos mentais que conservamos de tal objeto ou coisa. $\mathrm{O}$ processo de sedimentação desse conhecimento pode ser visualizado na forma como aprendemos matemática, ou alguma disciplina exata como a estatística. Ao estudarmos um cálculo de desvio padrão, uma medida de variabilidade estatística, por exemplo, podemos nos questionar sobre como o inventor de tal fórmula chegou ali. Ao "entendermos" a fórmula (nota-se um conhecimento, aqui do exemplo, cumulativo, a última verdade sobre aquele fenômeno), passamos a testá-la em pesquisas, já familiarizados com seu objeto, com sua forma, e tomamos esse processo de familiarização como conhecimento - o mesmo fazemos com conceitos como os de democracia ou moral -. Sendo assim, quando aprendemos a fórmula de um desvio padrão, é porque demos muitos passos mentais para alcançarmos sua equação e sua prova e, passada essa fase, muitas vezes somos incapazes de repetir a prova daquela elaboração numérica, porque, mais uma vez, o conhecimento (e a inquietação de Husserl com esse processo) é a sedimentação de processos mentais anteriores.

A partir de todo o dito, filosoficamente, ao que interessa à fenomenologia de Husserl o que denotamos? Ao que parece, tais preocupações entram em cena na medida em que esses fenômenos são elevados à consciência. Outros temas também surgem à sua reflexão, a exemplo da experiência pré-predicativa, ocorrida por experiências de choques e surpresas, ou seja, quando algo ocorre e levamos certo tempo para assimilar ou interpretar o que aconteceu, a dar um "predicado ao que experimentamos" [Ibid, p. 658]. Husserl buscou demonstrar como todas as experiências possuem certa base pré-predicativa, já que as experiências precisam ser interpretadas.

De outra face, Husserl desenvolve o conceito de eidos. O termo tem procedência grega e significa essência, forma, ideia. Na abordagem eidética, que se contrapõe a uma abordagem empírica, o eidos de alguma coisa é a junção, combinação, de características sem as quais aquela coisa 
Fenomenologias de Edmund Husserl e Alfred Schütz em contribuição à metodologia sociológica

seria diferente do que é. Segundo Husserl, para encontrarmos o eidos, devemos proceder pela "variação livre na imaginação", isolando determinadas características ao eidos acrescentadas. Por isso, Husserl propõe uma ciência eidética, que vai de encontro a uma visão empírica na medida em que a fenomenologia não se debruça sobre os objetos em si, mas sim, sobre seus significados, diferentemente de uma abordagem apenas empírica que se dedica a coisas e aspectos, dedução e generalização. [Ibid, p. 659].

Ao ambicionar a fenomenologia como método, Husserl focaliza a construção de uma ciência da essência do conhecimento. Logo, sua proposta de uma fenomenologia transcendental almeja analisar os fenômenos da consciência porque, para a filosofia husserliana, é necessário enaltecer a experiência do ego individual na tentativa de chegarmos a essa essência do conhecimento. Para o autor, a fenomenologia buscava a essência via um processo de redução, que colocava em suspensão o mundo exterior e a consciência individual. Para tanto, Husserl propõe a redução fenomenológica como método de acesso, o que para Alexander (p. 244) é o meio pelo qual podemos estudar as estruturas essenciais da consciência pura. Essa redução é um meio de reflexão processado, primeiro, pela eliminação de noções preconcebidas atreladas à natureza última do objeto. Para Husserl, é necessário suspender a crença do mundo exterior, colocá-la entre parênteses para que seja possível a realização da redução fenomenológica. Com isso, eliminamos suposições ontológicas e damos vez aos processos de consciência humana, que indicam as unidades de sentido. Em outros termos, a redução fenomenológica é o "voltar às próprias coisas", é o mundo da experiência que se transforma no mundo da aparência. O processo de redução, retrocesso, deve eliminar elementos empíricos e psicofísicos, ignorando o lado factual do fenômeno ao se descobrir a eidos da experiência [mais que a função ou existências das coisas, sua essência], como vista, a fenomenologia eidética. Sendo assim, o processo de redução fenomenológica suspende não somente o mundo exterior, mas também a consciência individual, em um estágio mais 'avançado' dessa redução que, nada mais é, que a proposta de Fenomenologia Transcendental de Husserl citada acima. Para ele, apenas após tais etapas de redução que podemos alcançar a estrutura suprema da consciência. 
Marina Félix de Melo

Em certa medida, podemos dizer que Husserl seleciona as características que considera primordiais para o surgimento de uma compreensão dos atos intencionais que constituem a consciência. Surge, então, um dos pontos fulcrais de seu pensamento: o conhecimento filosófico só é possível por uma dúvida perene, interrogante, uma vez que é capaz de colocar em suspeição sua própria maneira de conhecer, propondo um retorno à consciência. A ontologia da fenomenologia de Husserl propõe o ser dos entes, seu sentido e suas modificações. [Kearney, 1993].

Husserl rejeita os métodos de indução e dedução. O primeiro, em sua concepção, diz respeito à imaginação como objeto de experimentação empírica, já o segundo, se refere a uma imaginação concebida de acordo com determinadas pressuposições lógicas. Seu método fenomenológico parte do ponto de que existem ordens de consciência [como a imaginação] que podem ser entendidas de acordo com uma única reflexão, afastadas de premissas empíricas e racionalistas. [Ibid].

No que diz respeito às imagens, o autor procura superar o dilema destas como 1. algo interno da consciência (imanentismo) versus 2. algo externo da consciência [positivismo], argumentando que a imagem não é, exatamente, uma coisa. Sua fenomenologia redefine a imagem como uma relação, como uma ação da consciência voltada a um objeto além da consciência. As imagens são atos determinantes da consciência, ou seja, não determinam a consciência e não podem ser confundidas com meros resíduos de sensação que fornecem suporte para o pensamento, pois elas já são em si, intenções. Entrementes, como ressalta Kearney (1993), imagens e percepções são diferentes, sobretudo, em suas formas de apresentação, ainda que possam significar o mesmo objeto e estejam concatenadas com o objeto significado/intentado.

Kearney ainda problematiza a percepção que Husserl tem sobre a imaginação, um modo sui generis de consciência intencional. Isto ocorre na medida em que a imagem se figura como um modo espontâneo de significar um objeto. Em paralelo a isso, o 'percepto' é direcionado a um dado objeto existente que define o que vemos. Diferentemente da imaginação, em que o objeto é dado irrealmente, na percepção ele precisa ser dado realmente. Certa vez que para Husserl as coisas precisam ser apreendidas em suas essências, compreendidas em suas realidades e possibilidades, é a imaginação que possibilita as coisas serem libertas de 
Fenomenologias de Edmund Husserl e Alfred Schütz em contribuição à metodologia sociológica

seus status de contingência $\mathrm{e}$ as proporciona um status ideal de possibilidades de que cada fato seja uma instância única, singular.

A preocupação com a essência, mais uma vez, entra em cena na filosofia husserliana que acredita que a verdade pode ser alcançada via a intuição de essências ideais. Nessa perspectiva fenomenológica, as essências são como idealidades e as imagens assumem uma posição de destaque face à percepção, pois, têm a liberdade que abre um campo de possibilidades para as essências. Ao mesmo tempo, a imaginação é uma espécie de contemplação do que é performatizado na ação intencional da representação. Todavia, ainda que a imaginação nos liberte do reino dos fatos, é preciso que a persigamos em acordo com a essência das coisas, o que, em certa medida, soa como um paradoxo, pois, a imaginação é livre.

Numa percepção global, o que nos chama atenção na forma como Husserl ergue sua perspectiva fenomenológica? O que nele nos atrai, nos inquieta e se coloca como um problema para que ainda voltemos à sua filosofia quando estudamos fenomenologia em sociologia? Seria meramente porque ele foi um precursor dessa perspectiva? De fato, não. Aproveitando suas próprias elaborações sobre as imagens que traçamos, poderíamos ter utilizado a liberdade citada acima para nos dedicar a outras perspectivas filosóficas ou outros autores. Entretanto, é a própria "confusão" que Husserl levanta sobre como aplicar uma filosofia de modo cientificamente rigoroso que nos chama ao debate.

Comumente, escutamos que a filosofia é a base para ciência e, sobretudo, para as ciências sociais de uma forma geral. Quando um filósofo nos propõe uma ciência eidética, propõe mais que outra forma de se conceber e articular o conhecimento, pois, como vimos, planeja-se aí uma abordagem que se afasta do empirismo, mirando suas lentes para os significados e as essências. Por um momento, paramos a pensar: então, o que é ciência? O que Husserl entende por ciência e o que entende por filosofia? O grande problema que daí advém é que essas fronteiras são elaborações muito próximas. Entrementes, seria um erro se misturássemos essas duas concepções (filosofia e ciência), pois, findaríamos por eliminar diferenciações fulcrais do campo metodológico. Se considerássemos ciência e filosofia como a "mesma coisa", nem haveria necessidade para a redação destas páginas, não precisaríamos consultar dois autores para investigarmos sobre fenomenologia em sociologia. 
Marina Félix de Melo

Certo dia, ao pensarmos sobre onde estaria um problema que justificasse estudar esses dois autores (e não apenas um), conversamos brevemente com um filósofo de uma universidade do sul do País que, em tom irônico, disse: "Estudar Husserl? Ah, ele era o filósofo que queria fazer ciência... queria fazer da filosofia uma ciência, imagine...". Depois desse "espanto", o primeiro passo que demos foi entender o porquê de tal reação, o porquê de Husserl, vindo da matemática e passado a se dedicar à filosofia, tentaria fazer ciência com a filosofia fenomenológica. Ao que pudemos notar, arriscamos dizer que a própria trajetória do autor o levou a tal tensão, pois, como vimos, sua obra é fruto do egocentrismo da filosofia européia em um recorte temporal no qual a rigidez e a objetividade eram símbolos da crise intelectual da Europa, da mesma maneira em que a instabilidade e a ansiedade que rondavam o contexto estadunidense davam partida aos estudos pragmáticos que lidavam com problemas sociais sólidos como os da cidade de Chicago. Paralelamente, nota-se que a proposta de ciência eidética de Husserl é, também, inspirada no clássico Platão, que já presumia a necessidade de uma 'suspensão', base da fenomenologia husserliana e que se cristalizou em uma perspectiva ocidental de ciência. Por isso, ao tentar dominar a intencionalidade da consciência e/ou enxergar a filosofia como uma ciência rigorosa, Husserl se afasta de uma distinção segura do que seriam ciência e filosofia e finda por nos proporcionar uma visão porosa entre estas duas esferas do saber. Talvez, a busca por uma estrutura suprema da consciência não seja uma preocupação apenas científica, mas sim, uma preocupação que pode ser tratada a partir destas duas grandes formas de conhecimento, mesmo porque não existe um modelo único e consensual do que seja ciência, embora este não seja o foco destas páginas.

A partir disso, não vemos como um empecilho ao entendimento das propostas e contribuições de Husserl o "passeio" pelas duas esferas de saber, o que tomamos como uma conseqüência de sua conjuntura. Não entendemos, também, que seria melhor ou pior para nossa leitura se ele estivesse mais no plano filosófico ou científico sociológico. No entanto, não negamos que as diferentes leituras do como pensar e agir fenomenologicamente estão expostas a conseqüências, sobretudo, de como podemos articular a fenomenologia em nossa visão de mundo. Por isso, nos propomos a entender a partir das lentes de Schütz o foco de uma fenomenologia sociológica, tendo em vista que este último parte não 
Fenomenologias de Edmund Husserl e Alfred Schütz em contribuição à metodologia sociológica

apenas de outro ponto contextual, mas também que pôde problematizar algumas questões não lapidadas por Husserl como a problemática da subjetividade, pois, Husserl estava preocupado com o mundo da vida que, para ele, nos explicava porque temos experiências compartilhadas, o que o levou a toda construção mencionada acima.

\section{Alfred Schütz (1899 - 1959)}

Considerado como um filósofo social, Alfred Schütz nasceu na Áustria, estudou direito em Viena e em 1939 mudou-se para os Estados Unidos, onde fez parte da New School for Social Research. Ao se dedicar à fenomenologia, estudou metodologia das ciências sociais, bem como a fenomenologia de Husserl e de outros filósofos.

Na revisão de sua obra, utilizaremos como principal guia o livro “Fenomenologia e Relações Sociais” (1979), organizado por Helmut R. Wagner que consiste em uma reunião de textos escolhidos de Schütz. Em verdade, nos interessamos pelo formato que o autor dá à fenomenologia para as ciências sociais, em como ele entende que a fenomenologia pode ser utilizada pela sociologia a partir de leituras que realizou, sobretudo, da filosofia husserliana. Na tentativa de casar sociologia com fenomenologia, Schütz se utiliza de conceitos weberianos, demonstrados em 1932 no livro "Phenomenology of the social world". Segundo Wolff, tem sido comum nos Estados Unidos, nos estudos mais recentes que recuperam as contribuições de Schütz e sua fenomenologia, que a importância da influência de Max Weber sobre o autor seja esquecida ou delegada a segundo plano. Em "Phenomenology of the social world", logo no início do livro, Schütz aborda como apesar da filosofia de Weber ter figurado como um verdadeiro ponto de partida para as ciências sociais, suas análises não foram à profundidade de onde as tarefas importantes dos estudos humanos podem ser realizadas [Schütz apud Wolff, 1980, p. 671].

Por uma necessidade de esclarecermos alguns conceitos que utilizaremos na tentativa de fazer a ponte do pensamento de Weber com o de Schütz, ou mesmo para entendermos sua fenomenologia dentro das ciências sociais, voltaremos em dois tópicos essenciais para o pensamento deste autor, a saber, o mundo da vida e o estoque de conhecimento.

O mundo da vida cotidiana de Schütz diz respeito, em primeira instância, ao mundo da atitude natural, vivenciado como realidade nessa 
Marina Félix de Melo

"atitude natural". [Schütz, 1979, p. 72]. Este mundo da vida é intersubjetivo e existe antes de nós, nos é dado por ser interpretado e vivenciado por outros e, por ora, se dá às nossas interpretações e experiências. Schütz sintetiza: "Toda interpretação desse mundo se baseia num estoque de experiências anteriores dele, as nossas próprias experiências e aquelas que nos são transmitidas por nossos pais e professores, as quais, na forma de 'conhecimento à mão', funcionam como um código de referência". Sendo assim, quando o autor versa sobre a atitude natural, não se refere a um mundo privado, todavia, a um mundo comum a todos, compartilhado, do qual não surgem apenas interesses teóricos, mas sim, práticos. Por isso, o mundo da vida cotidiana de Schütz é a cena e o objeto de nossas ações e interações, pois, os motivos que guiam nossa atitude natural são motivos pragmáticos que nos levam a mudar esse mundo e a ser mudado por ele.

Sobre o estoque de conhecimento, podemos dizer que se trata de um conjunto de experiências passadas e atuais, o que nos antecipa a ocorrência de eventos cotidianos. Se Husserl já envolve estas noções a partir do que entende por "sedimentação do significado", Schütz se preocupa em demonstrar como esse estoque de conhecimento possui uma estrutura especial ao mesmo tempo em que não é homogêneo. Assim, para o autor, existem esferas, gradações, em nossa mente nas quais estão presentes obscuridade de ideias e ambiguidades, seguidas de áreas de preconceitos, crendices etc, da mesma forma em que existem regiões de nossa mente que ignoramos, como que por um processo seletivo.

(...) é o problema em particular do qual nos ocupamos que subdivide nosso estoque de conhecimento à mão em zonas diferentes de relevância para a sua solução e estabelece, assim, os limites das várias zonas do nosso conhecimento mencionadas acima, ou seja, zonas de nitidez e de vagueza, de clareza e obscuridade, de precisão e ambiguidade. [Schütz, 1979, p. 72].

Olhamos essa divisão de Schütz com certo estranhamento porque, apesar de didaticamente esclarecedora, não acreditamos ser possível a separação entre tais esferas justamente pela capacidade seletiva de que 
Fenomenologias de Edmund Husserl e Alfred Schütz em contribuição à metodologia sociológica

disporíamos, encontrada nas entrelinhas de seus texto, quando ele coloca que algumas dessas áreas, zonas, são ignoradas em nosso processo mental. Isto é, acreditamos, por ora, ser inviável a aplicação dessa divisão em zonas mentais na interação do sujeito com o mundo da vida cotidiana. Exemplificando nossa dificuldade em trabalhar a partir dessas divisões de Schütz, poderíamos pensar que nossas manifestações preconceituosas são expostas a partir de, e conjuntamente a, processos ambíguos. Entretanto, este ponto não nos parece tão relevante no momento, haja vista o principal objetivo que Schütz tem ao apontar a ideia de estoque de conhecimento, que é o de demonstrar que este é a chave de uma interpretação pragmática da natureza do que conhecemos. A tudo isso, o autor soma que o estoque de conhecimento se apresenta em um fluxo contínuo e que está sujeito a modificações ininterruptas, pois, acrescentamos experiências a cada dia e temos a capacidade de reinterpretar tanto as experiências novas como as passadas, o que altera não apenas a extensão desse estoque, mas também sua estrutura. Em suma: "é o estoque de conhecimento à mão que serve como código de interpretação da experiência atual em curso. Essa referência a atos já vivenciados pressupõe memória, e todas as suas funções, tais como lembrança, retenção, reconhecimento." [Schütz, 1979].

Agora que passamos, brevemente, por estes dois conceitos elementares da obra de Schütz, podemos observar como o autor, a partir de Weber, mergulha na compreensão do que seria subjetividade, algo que, como já notado, não foi foco de maiores atenções por parte de Husserl. Schütz investiga o significado subjetivo de um produto, observando que para que possamos entender o produto, antes, precisamos ter em vista o contexto-significado do produtor que o gerou, o que o leva a falar de uma "situação biográfica determinada" [Schütz, 1979, p. 73]. Após isso, examinaríamos a simultaneidade ou quase-simultaneidade do todo, os "Atos" 2 politéticos nos quais tais experiências foram acumuladas. Para ele, esse "contexto-significado" diz respeito às experiências significativas do sujeito, ou seja, nossas experiências significativas se encontram em um dado contexto-significado na medida em que se colocam em uma síntese superior, por atos politeticamente articulados. [Wolff, 1980, p. 671]. A simultaneidade das "durées" de Schütz se referem à capacidade que temos

2 Schütz entende "Ato" [com A maiúsculo] como uma atividade não especificada, diferentemente de ato, que é um produto da ação. 
Marina Félix de Melo

de compreender nosso contexto e o do outro como uma realidade absoluta. Logo, não somos capazes de entender apenas nosso contexto, mas podemos estender a simultaneidade de duas "durées". Tentemos exemplificar: se produzimos uma dissertação ou tese de pós-graduação, nosso objetivo é fazer com que quem leia tal trabalho compartilhe conosco seu contextosignificado. O processo de simultaneidade que nos dá uma relação compartilhada do que nós e o leitor compreendemos daquelas páginas escritas.

Ainda sob influência weberiana, Schütz trabalha o conceito de "entendimento", mas antes disso, convém localizarmos a distinção entre "significado subjetivo" e "significado objetivo" em sua obra. Voltemos ao exemplo das dissertações e teses de pós-graduação. Ao analisarmos uma tese, temos como significado objetivo o pensar em que época esta foi escrita, sobre qual contexto histórico, contexto de gênero, o porquê daquele tema em determinado departamento etc. Já como significado subjetivo, temos questões relacionadas a "o que o autor estava pensando quando escreveu isso?", "o que ele tenta demonstrar com tais argumentos?”, “o que presume a partir de tais pressuposições?", ou mesmo, "o que sente diante de tal problema?". Para um trabalho nas ciências sociais essa distinção, salienta Schütz, é muito importante e, por isso, deveria ter sido melhor lapidada por Weber. Concordamos com Schütz que tal distinção é necessária, sobretudo, quando lidamos com problemas e objetos tão plásticos como os sociológicos, isto é, a plasticidade de nossos temas faz com que as perguntas objetivas e subjetivas estejam imbricadas, concatenadas e interdependentes para o tipo de raciocínio que nos dispomos ter ao pegarmos a dissertação ou tese do exemplo, ou ainda se recorrêssemos a demais criações literárias. No entanto, o limite com que Schütz se depara é: o que faz com que um conhecimento seja de tipo objetivo? Sua aceitação geral? Seu compartilhamento maior em uma cultura de pesquisadores de ciências sociais? Aí reside um problema de significados, pois, se a noção de que é necessário suspender a cultura em uma redução fenomenológica [a partir de um estoque de conhecimento] for um conhecimento objetivo para daí se chegar às questões subjetivas, o próprio princípio de suspensão passa a ser falho porque ele próprio (se é preciso suspender a cultura) precisaria ser suspenso. Teríamos de "voltar às próprias coisas" que, pela elaboração de Schütz, entendemos que é chegar ao significado subjetivo das coisas. Eis quando pensamos: se a 
Fenomenologias de Edmund Husserl e Alfred Schütz em contribuição à metodologia sociológica

fenomenologia, então, for um conhecimento subjetivo à sociologia, vamos suspender a própria cultura fenomenológica.

Em Schütz, para chegarmos ao significado subjetivo ou objetivo das coisas temos de usar tipificações ao passo que mesmo que o outro esteja presente conosco, ao nosso lado, não podemos entendê-lo por completo, independentemente do grau de relação que tenhamos com ele. Logicamente, a capacidade de se aproximar do significado subjetivo do outro varia de acordo com o tipo de relação que temos com este. Assim, o entendimento que temos sobre "quem é" o professor com quem tivemos aula certa vez há alguns anos, em um processo de socialização apenas secundário, é ínfimo se comparado com o entendimento que temos sobre "quem é" nossa amiga próxima, pois, desta última, podemos prever com mais clareza como se comportaria diante de determinadas situações, por exemplo. Todavia, como ressalta Schütz, não podemos conhecer ninguém de um todo, nem mesmo nossa grande amiga do exemplo, pois, ela será apenas um tipo para nós, mesmo que ainda refinado e concreto. Não temos como chegar a seu significado subjetivo puro, poderemos, apenas, nos aproximar desta em uma mistura com seu significado objetivo porque não somos o outro (a outra).

Em "Das realidades múltiplas" (1945), inspirado na obra "Principles of Psychology" (1890) de Willian James, Schütz levanta as características básicas do que seria o "estilo cognitivo" de um mundo: "1) uma tensão específica da consciência; 2) uma epoché específica; 3) uma espontaneidade predominante; 4) uma forma específica de experiência do próprio eu; 5) uma forma específica de socialidade; e 6) uma perspectiva temporal específica" [Schütz apud Wolff 1980: 674]. Estas características dizem respeito a um dos pontos mais importantes a que se dedicou o autor, ao "cenário cognitivo do mundo da vida" [Schütz, 1979, p. 77]. Para ele, é a epoché do mundo da teoria científica que a difere do mundo da vida cotidiana, pois, essa epoché tem significação especial na medida em que é de um mundo científico mediado pela noção de suspensão fenomenológica, ou seja, da forma como Schütz concebe ciência. O problema que daí Schütz abstrai é como pode a sociologia apreender o homem, sua humanidade e a relação deste homem com os outros se o sociólogo está, também, imerso no mundo da vida? Essa contradição é trabalhada em "Phenomenology of the social world", texto no qual o autor sugere que o cientista social construa um recurso artificial para dar conta de um mundo-vida intersubjetivo. Dito 
Marina Félix de Melo

de outra maneira, ele propõe este recurso artificial como um método para as ciências sociais que superaria tal impasse dialético, tendo este recurso de estar associado aos postulados de: coerência lógica; interpretação subjetiva e adequação. A este passo, Schütz se aproxima dos tipos ideais weberianos.

Na mesma obra, "Phenomenology of the social world", Schütz reconhece que existem análises realizadas a partir de um plano mundano que não precisam da redução fenomenológica, ou seja, esta última não é uma regra que se aplica a todas as situações e análises. Inclusive, na introdução do livro, Schütz admite que apenas em um de seus capítulos trabalha sob tal suspensão, ao fazer um estudo dos fenômenos da constituição na consciência temporal interna do ego solitário. Logo, o restante do texto é baseado no mundo da vida, sem um conhecimento transcendental, numa outra linha do fazer (aqui, o fazer ciência social passa a operar a partir das características que o cientista social precisa ter, já mencionadas, e de saber articular e reconhecer as necessidades de suas problemáticas).

Wolff, na tentativa de entender as contribuições de Schütz para a ciência social, versa que o cientista social não interage com as pessoas que estuda, mas apenas as observa em relação à tipificação que molda para tal, comparando suas observações com tais tipologias [mais uma vez, a marca weberiana salta aos nossos olhos]. Sobre o cenário criado por Schütz, o sociólogo, por exemplo, trabalharia de forma determinada pelas preocupações da vida mundana - suspensas na epoché do cientista. O problema é que, para Wolff, se o outro não puder ser estudado sem ser pela tipificação (na esfera mundana ou na epoché do cientista), como poderia Schütz falar em significado subjetivo? "Que acesso ao outro, capaz de possibilitar isso, está oculto por trás de tal suposição?" [Wolff, 1980, p. 676]. Apesar de extremamente relevante a observação de Wolff, nos preocupa a maneira como ele se baseia em Schütz para desenhar o fazer sociológico, aparentando não considerar algumas pesquisas que possuem campos peculiares, bem como a percepção de observação participante que, à época, já tinha sido "jogada à mesa" da ciência social pelas contribuições de Malinowski no "Argonautas do Pacífico Ocidental" de 1922, por exemplo. Wolff demonstra como o significado subjetivo do outro não pode se limitar a uma abordagem meramente cognitiva, mas que também deve ser pensada em termos afetivos, por elementos como amor e ódio. 
Fenomenologias de Edmund Husserl e Alfred Schütz em contribuição à metodologia sociológica

De toda forma, a interpretação sugerida por Wolff sobre Schütz não diminui sua compreensão das bases da indagação científico-social, reconhecida pelo próprio Wolff, uma vez que Schütz levanta a natureza elíptica dos conceitos weberianos básicos, bem como desperta nosso olhar para acontecimentos triviais do cotidiano como comer, dormir, conversar, dentre outros infinitivos e outras atividades que nos levam, a partir da análise de fenômenos desse tipo, aos estudos etnometodológicos. Em verdade, o trabalho de Schütz ficou mais conhecido a partir da década de 1960 pela etnometodologia, considerada por muitos como uma sociologia mais fenomenológica.

A principal perturbação que fomentou este trabalho foi tentar entender como a filosofia fenomenológica de Husserl pôde ter influência na concepção de sociologia fenomenológica de Schütz e como esse processo se relaciona com a sociologia de uma forma geral. Como a fenomenologia chega na sociologia? Como se dá a relação entre a sociologia e a abordagem 'humanista-culturalista' da fenomenologia? Para Husserl, a relação entre fenomenologia e ciência social está na relação entre as tendências antropológicas e transcendentalistas. A tendência antropológica acredita que a filosofia precisa de uma base subjetivista, vinda da psicologia. Já a transcendentalista, que uma ciência que se debruça sobre a subjetividade transcendental deve ser a base de todas as ciências [incluindo a psicologia]. Husserl (assim como Schütz) prima pelo segundo panorama, afinal, acredita que a ciência que fundou, a fenomenologia transcendental, seria a base de todas as demais ciências.

A questão da subjetividade, que fora deixada de "lado" por Husserl, toma um formato amplo na obra de Schütz, que envereda pelo caminho da consciência, dos processos internos, tarefa que consideramos ser um dos grandes "acabamentos" que Schütz faz na obra de Husserl. Todavia, vale lembrar que se Schütz ergue sua fenomenologia baseado em Husserl, chega a outro ponto em que se distancia da fenomenologia transcendental do filósofo alemão para dar formato a sua análise constitutiva da atitude natural. Este foi o principal acontecimento que nos chamou às perguntas mencionadas acima, pois, este descolamento de Husserl - que pode ser visto como uma "superação" de Schütz - produziu conseqüências (também para a etnometodologia e, em parte, para a hermenêutica) como os limites em tratar a ação meramente como significado [e não como práxis]; ignorar a centralidade do poder na vida social; e, desprezar a importância de que 
Marina Félix de Melo

normas sociais podem ser interpretadas de acordo com divisões de interesse [Wolff, 1980, p. 690]. Vemos tudo isso como mais que uma superação de um autor a outro. Tomamos estes limites e o "ir e vir" de quando pensamos uma dada perspectiva a partir de dois autores como frutos do amadurecimento da perspectiva como um todo e não seu enfraquecimento.

Ao repensarmos esse movimento de "limitações e avanços", vamos ao ponto de que a fenomenologia passa, então, a ter de realizar duas tarefas para as ciências sociais: a de plantar uma base para sua ciência, algo que Husserl e Schütz já acreditavam ter realizado, e analisar a constituição do mundo da vida. Isso, evidentemente, se partirmos do pressuposto de que a finalidade das ciências sociais (e, logo, da sociologia) é compreender o mundo da vida social. Para um debate mais aprofundado dessa problemática, provavelmente teríamos de chamar Habermas à cena, pois, este discorda de Husserl e Schütz (que enxergam o mundo da vida como possivelmente separável da esfera material). Para Habermas, a consciência é inseparável das circunstâncias materiais.

No processo da relação "fenomenologia e sociologia", tanto Husserl, quanto Schütz, possuem limitações nas bases de suas obras. Se entendemos que Husserl não encontrou seu eidos por não enveredar por processos intersubjetivos em seus estudos, tento em vista que a fenomenologia surgiria justamente do processo de suspensão da intersubjetividade, podemos dizer, também, que Schütz aparenta se basear mais em um conhecimento empírico do que fenomenológico, ainda que seu esforço estivesse no afastamento desta. Lembremos que se, de um lado, Husserl estava preocupado em "fazer da filosofia fenomenológica uma ciência", Schütz estava voltado a justificar a aplicação de seu método fenomenológico nas ciências sociais, o que parecia uma tarefa espinhosa e desafiadora. Estas preocupações dos autores se assemelham às de Durkheim ao tentar legitimar a cientificidade e a objetividade da sociologia que, também, limitaram seu pensamento. De um todo, e embora sob tais conjunturas, a fenomenologia nas ciências sociais possibilitou a essa última a quebra do dualismo corpo e mente da visão cartesiana, até então em voga, ao proporcionar o esclarecimento ou suspensão do mundo da vida, já 
Fenomenologias de Edmund Husserl e Alfred Schütz em contribuição à metodologia sociológica

indicando que a pedra cartesiana era resultado de uma crise de legitimações dentro das ciências sociais, da sociologia ${ }^{3}$.

As pretensões de Schütz nos levam à outra problemática que, provavelmente, não enxergaríamos apenas na fenomenologia pura husserliana, transcendental: a do empirismo. Se Schütz propõe a fenomenologia ao mesmo tempo em que é acusado de seguir pelo conhecimento empírico das ciências sociais, perguntamos se não seria um contra-senso, um paradoxo, a junção dessas noções (empiria com um empreendimento filosófico). Porém, o que faz com que não seja [o que por estas leituras não conseguimos enxergar] é o próprio entendimento de empírico, que não pode ser confundido como sinônimo de uma abordagem positivista-naturalista. Empírico não quer dizer algo que não precise de revisão [Wolff, 1980, p. 683] e, apesar de não entrarmos, por ora, nessa discussão, vemos que esta tensão é quem nos leva a pensar não em fenomenologia sociológica, mas sim, numa Metassociologia. Isto se dá, sobretudo, quando Schütz coloca a explicação objetiva do meio a partir de experiência lógica, interpretação subjetiva e adequação. Alargando um pouco nosso espectro, poderíamos dizer que a própria noção de sociologia empírica se coloca imóvel, fixa, em alguns textos, como se não pudessem haver outros tipos de sociologia, como se todas partissem das mesmas bases ontológicas. Isso nos levaria aos antigos e sempre atualizados debates sobre a objetividade das ciências sociais, se uma sociologia "não empírica" poderia ser objetiva. Eis então quando as "confusões" em reconhecer Schütz no campo da fenomenologia, da sociologia, ou dos dois, enriquece nossas questões diante de todo o dito. Possivelmente, precisaríamos da noção de suspensão de Husserl para entender as fronteiras porosas dessas percepções, mesmo porque a fenomenologia aqui desenhada sugere uma suspensão da própria sociologia na medida em que a realidade objetiva da sociedade é experimentada de forma subjetiva pelo indivíduo - o que não foi uma novidade da fenomenologia, estando esta preocupação presente em voga desde Feuerbach, Marx e Weber.

\footnotetext{
${ }^{3}$ Para Descartes, os sentidos enganam, logo, o "estoque de conhecimento" vem dessa crítica.
} 
Marina Félix de Melo

\section{Considerações Finais}

A perspectiva fenomenológica é leitura imprescindível a todo e qualquer estudo de metodologia em sociologia. Poderíamos, em vez de trabalhar nestas páginas com Husserl e Schütz, ter optado por autores também muito importantes como Max Scheler, Heidegger, Sartre ou Merleau-Ponty, o que nos levaria a diferentes concepções do que é fenomenologia, diferentes métodos e resultados.

Apesar de fomentar a reflexão, a fenomenologia foi criticada por diversos autores. As críticas mais persuasivas e contundentes sobre a fenomenologia de Husserl, em especial, foram as feitas pela Escola de Frankfurt, sobretudo, por Adorno e Marcuse. Brevemente, podemos dizer que estes autores retomaram as noções de essência e aparência (ou essência e existência) desde Platão, Descartes e Kant para mostrar que a eidos husserliana é invariável. Da mesma forma, os autores também acusam Husserl de a-historicidade e de conceber uma relação pré-crítica com as coisas que estuda. Adorno acredita que o lema "volte às coisas", que aparenta ter a intenção de romper com o idealismo, finda por ser idealista, pois, em sua leitura, as coisas de Husserl estariam aprisionadas na consciência. Enfim, representantes da Escola de Frankfurt, de uma maneira geral, acreditavam que a forma como Husserl ergueu a fenomenologia dava margem para que ela pudesse ter sido usada por autoritários ou totalitários, já que seria extremamente flexível e porosa.

Embora tais críticas sejam fundadas, essencialmente dentro da lógica da Escola de Frankfurt, assim como outras como as lançadas por Lukács que via certo "irracionalismo" na fenomenologia, acreditamos que talvez fosse necessária uma leitura husserliana do próprio Husserl, que abre alas ao questionamento e à possibilidade de dúvidas. Embora concordemos em parte com as preocupações esboçadas pelos frankfurtianos, acreditamos que seria mais interessante trazer à fenomenologia contribuições como a abordagem lingüística de Wittgenstein, pois, assim, poderíamos imaginar uma abordagem fenomenológica para além dos limites da análise da consciência.

Mesmo mediante as limitações mencionadas, uma das melhores contribuições que enxergamos nos estudos fenomenológicos para a sociologia reside na grande atenção que esta perspectiva dá à Dúvida, ainda que a Dúvida seja tratada sob outras perspectivas, como pelo 
Fenomenologias de Edmund Husserl e Alfred Schütz em contribuição à metodologia sociológica

pragmatismo, por exemplo. O que nos chama a atenção é a forma como a fenomenologia trata a Dúvida, a posição de destaque que esta tem em sua edificação filosófica. A Dúvida é o primeiro passo na construção do conhecimento na medida em que é por ela que podemos perceber nossos objetos de estudo. Um exemplo disso é a maneira como Husserl acreditava que devemos duvidar de tudo, menos de nossos próprios pensamentos (menos na capacidade de duvidar). Em sua fenomenologia, a dúvida está dentro da mente do indivíduo, logo, podemos duvidar que "este computador, este papel, se coloca em nossa frente, que é real", assim, é o momento em que podemos duvidar até mesmo de nossa experiência.

Poderíamos realizar aqui um levantamento maior sobre as limitações e contribuições da fenomenologia à elaboração sociológica, porém, o que mais nos preocupa é saber como podemos lidar, em nossas pesquisas, com perspectivas diferentes (fenomenologia, pragmatismo etc). $\mathrm{O}$ primeiro cuidado a ser tomado ao nos depararmos com tantas opções, que pressupõem bases ontológicas distintas, está em perceber os sentidos polissêmicos das diversas perspectivas, teorias e autores. Como vimos, mesmo dentro da fenomenologia, Husserl e Schütz poderiam fornecer contribuições variadas a um determinado tipo de pesquisa. Sendo assim, como lidaríamos com teorias diferentes já que apenas uma não daria conta de um dado objeto de pesquisa? Adotaríamos duas ou mais? E se essas partissem de bases ontológicas dessemelhantes? A flexibilidade em como articulá-las em um problema real de investigação sociológica dependerá da sensibilidade do pesquisador, bem como de sua experiência, porque se o marco teórico de uma pesquisa for um mero recorte não articulado destas, provavelmente não poderá responder aos problemas sociológicos levantados. Por isso, é relevante pensarmos em tais escolhas a partir de perguntas ontológicas como: “o que é isso?" e epistemológicas: “como conhecer isso?".

Ao analisarmos como diversas perspectivas tentariam resolver tais problemas, veríamos, por exemplo, que a base do pragmatismo se ancoraria em um instrumentalismo ao entender que as teorias são ferramentas do pesquisador ou que diferentes formas de filosofia se erguem por preocupações, às vezes, muito díspares (o que diferenciou a filosofia européia da Escola de Chicago com seus problemas sociais concretos, à guisa de exemplo). Em suma, sob o cuidado em não "misturarmos" indiscriminadamente perspectivas ontológicas díspares, é o 
Marina Félix de Melo

diálogo entre as variadas possibilidades teóricas para a resolução de um problema sociológico que possibilita o trabalho do sociólogo. Seu trabalho não reside apenas na acumulação do conhecimento sobre distintas tradições clássicas e contemporâneas, mas sim, no pensamento dos problemas articulados em um complexo maior e entendendo quando estas questões teóricas e metodológicas entram em cena e contribuem para a pesquisa social.

No caso específico em se trabalhar com as fenomenologias de Husserl e Schütz, temos de considerar que este último abandona o programa epistemológico de Husserl mas, ainda assim, não consegue dar conta do problema da intersubjetividade que permanece espinhoso em sua obra. Embora tomando este como um dos nervos mais tensos da relação das fenomenologias de Husserl e Schütz com a sociologia, porque tal incompletude pode freiar o trabalho do sociólogo, avaliamos como importantes, por exemplo, a tentativa de Schütz de superar o empirismo e o solipsismo e consideramos que o "pensar fenomenologicamente" propiciou aos sociólogos maior sensibilidade nos campos teóricos de pesquisa. Em verdade, ainda que os autores não consigam dar conta da teoria social como um todo, acreditamos que uma tentativa mais próxima disto estará na etnometodologia, "filha da fenomenologia de Schütz, neta de Husserl".

\section{Referências Bibliográficas}

ALEXANDER, Jeffrey C. Twenty Lectures: Sociological Theory Since World War II. New York: Columbia University Press, 1987.

BRENTANO, Franz. Psichologic du point de vue empirique. Paris: Editions. Mointagn, 1944.

DESCARTES, René. Discurso do Método. 2.d. São Paulo: Escala, [1637].

HEGEL, Friedrich. Fenomenologia do espírito. Petrópolis: Vozes, 1992.

HUSSERL, E. Ideas: General Introduction to Pure Phenomenology. New York:

Collier Books, 1962. . Phenomenology and and the Crises of Philosophy. New York: Harper

\&Row, 1965. . The Idea of Phenomenology. The Hague: Martinus Nijhoff, 1970b. 
Fenomenologias de Edmund Husserl e Alfred Schütz em contribuição à metodologia sociológica . Husserl: Short Works. Notre Dame. In: University of Notre Dame Press, 1981.

. Ideas Pertaining to a Pure Phenomenology and to a Phenomenological Philosoph: First Book. Dordrecht: Kluwer, 1982.

KANT, I. Critique of Pure Reason. New York: St. Martin Press, 1965.

KEARNEY, Richard. Poetics of Imagining: From Husserl to Lyotard. New York: Routledge, 1993.

OUTHWAIT, Willian; BOTTOMORE, Tom. Dicionário do Pensamento Social do Século XX. Rio de Janeiro: Zahar Editor, 1996.

REALE, Giovanni; ANTISERI, Dario. História a Filosofia: do romantismo até nossos dias. 2.ed. São Paulo: Paulus. vol. 3, 1991.

SCHUTZ, Alfred. The problem of rationality in the social world. Economica, New Series, 10(38), 1943.

. "Symbol, reality and society". In: BRYSON, L. (org.), Symbols and society. New York, Harper, 1955.

Phenomenology of the social world. Evanston, Northwestern, 1967.

. "Bases da Fenomenologia”. In: SCHUTZ, Alfred. Fenomenologia e

Relações Sociais. Rio de Janeiro: Zahar. 1979.

WOLFF, Kurt H. “Fenomenologia e Sociologia". In: BOTTOMORE, Tom; NISBET, Robert [orgs]. História da Análise Sociológica. Rio de Janeiro: Zahar Editor, 1980.

\section{Enviado em: 02/03/2016}

Aceito em: 28/07/2016 